\title{
Hot tempers, hard core
}

\author{
Were the last dinosaurs wiped out when interplanetary debris hit what \\ is now the coast of Mexico? A drilling project that promised answers has \\ been plagued by squabbles over access to samples. Rex Dalton reports.
}

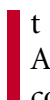
$\mathrm{t}$ should have been a geological fiesta. In April 2002, an élite group of scientists converged on Mexico City to examine one of the most important cores ever drilled from the Earth.

Since the previous December, local engineers had drilled 1,511 metres down into the Chicxulub crater on Mexico's Yucatán Peninsula, to extract cores of rock. Researchers hoped that these samples would help to solve one of the biggest mysteries in our planet's history - what caused the extinction of the last of the dinosaurs, together with most other species represented in the fossil record, some 65 million years ago.

The now-hidden crater, detected by anomalies in measurements of Earth's gravity and magnetism, was formed at about the same time, when a meteorite or comet hit the planet. Many researchers believe that this impact caused the mass extinction that saw off the dinosaurs by kicking up debris into the stratosphere, blocking sunlight and shutting down most photosynthesis on the planet. A minority disputes this theory, arguing that other events - such as volcanic eruptions, sea-level changes or a series of impacts were to blame for the spectacular loss of species that occurred at the transition between the Cretaceous and Tertiary periods, a time otherwise known as the K/Tboundary.

Samples from the crater should untangle the sequence of events associated with the Chicxulub impact, and help scientists to assess whether it could have caused the $\mathrm{K} / \mathrm{T}$ extinction. But last April's gathering, at the National Autonomous University of Mexico (UNAM), kicked off a prolonged period of acrimony, as researchers battled for access to segments of the core. In particular, one prominent proponent of the impact theory stands accused of delaying the acquisition of key core samples by other project scientists. And the row has been heightened by the claim from one of those scientists that these disputed samples cast severe doubt on the idea that the Chicxulub impact caused the mass extinction.

"Nothing is more political in science than
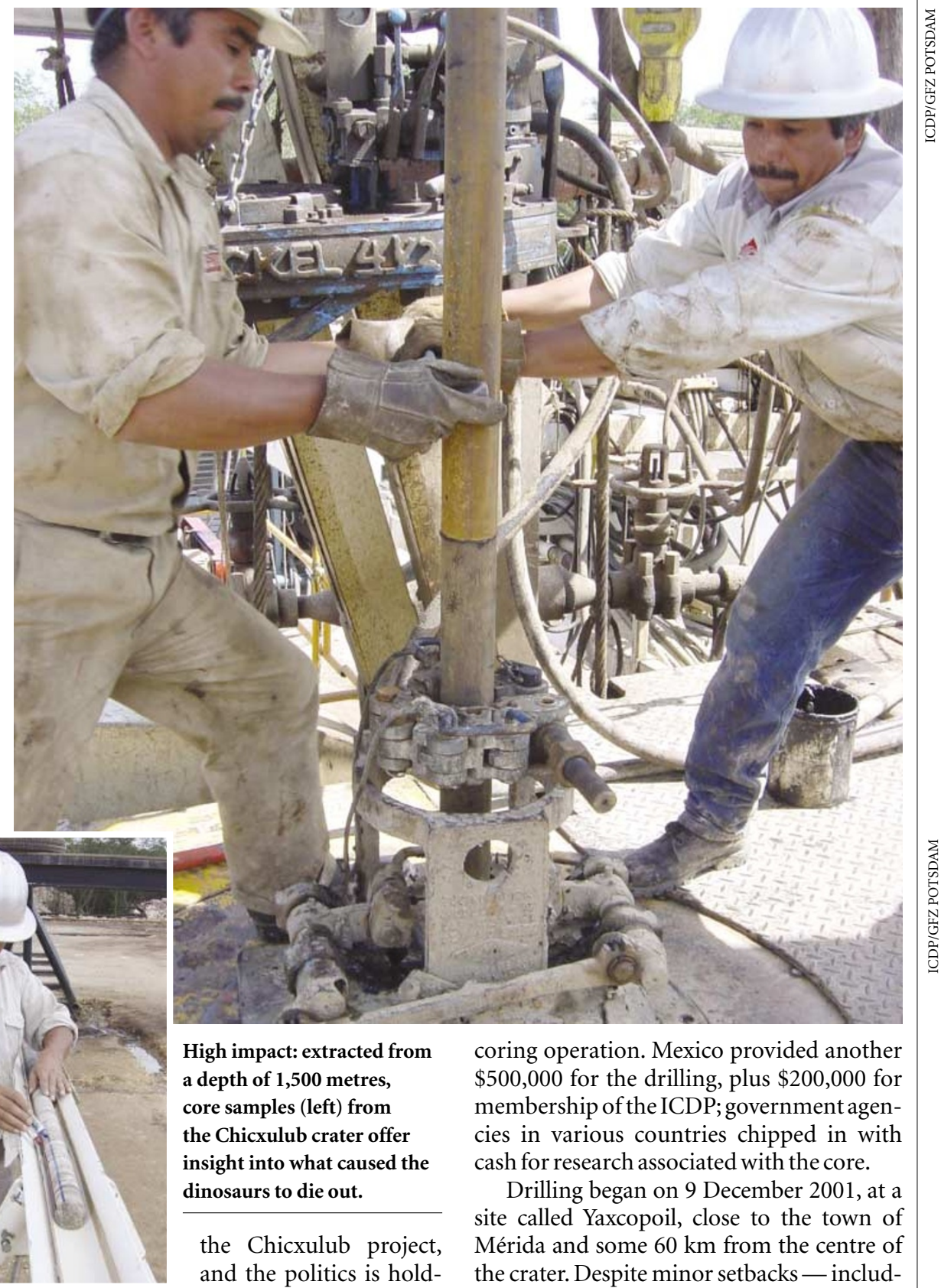
Natural Resources Canada in Ottawa, whose work was caught up in the row.

Efforts to drill into the Chicxulub crater suffered a decade of false starts because of funding difficulties. But eventually, the International Continental Scientific Drilling Program (ICDP), based in Potsdam, Germany, agreed to pump US\$1.5 million into a
High impact: extracted from a depth of 1,500 metres, core samples (left) from the Chicxulub crater offer insight into what caused the dinosaurs to die out.

the Chicxulub project, and the politics is holding back the science," 
was to divide the other halves into smaller samples for analysis of their chemical composition, mineral content and microfossils.

All eyes were on the boundary-core section from nearly $800 \mathrm{~m}$ deep, split by a thin green line. These deposits of a mineral called glauconite, the researchers knew, were laid down in marine sediments during the $\mathrm{K} / \mathrm{T}$ boundary. "They looked at that core and started drooling," says Buck Sharpton of the University of Alaska at Fairbanks, one of the Chicxulub project's six principal investigators. With other sections of the core, researchers were able to select their samples, secure them and leave. But with more scientists wanting samples from the boundary section than could be accommodated, things became heated.

So much so, in fact, that two principal investigators - Jan Smit, a geologist at the Free University in Amsterdam, and UNAM team leader Jaime Urrutia Fucugauchi clashed over Smit's plan to take the boundary section of the core back to the Netherlands and distribute it to project scientists from there. Smit argued that he could do a better job of cutting the core, which irritated the Mexican scientists. "I was very angry," says UNAM geologist Mario Rebolledo Vieyra.

\section{Rock stars}

Eventually, Urrutia relented. In June 2002, Smit took the boundary-core section to Amsterdam to cut specimens for analysis. The agreement, confirmed by Smit in a 3 July letter to Urrutia, was that Smit would distribute boundary-core samples to project scientists worldwide by 15 August, and return the remaining core material to Mexico by 15 September. But those deadlines were missed, and Urrutia says that he regrets entering into the agreement. "I now believe Smit wanted to control that segment," he claims.

Smit categorically denies this allegation and blames a busy schedule and poor communication from the scientists wanting $\mathrm{K} / \mathrm{T}$ boundary samples. Many of them, as it happens, were e-mailing or calling Mexico, believing the core section to be there. Urrutia admits that his team should have done a better job of informing project scientists that the samples were in Smit's lab. "There was a lot of misunderstanding," he says. "In retrospect, we should have communicated better." For his part, Smit concedes that he "waited too long" to send out the boundary-core material - one-third of the core, which should have been returned to UNAM, was still in his lab as Nature went to press.

As the months of 2002 slipped by, about a dozen researchers waiting for their boundarycore samples became progressively more nervous. They had another deadline to worry about - the 15 January 2003 cut-off for the submission of abstracts for a symposium on the Chicxulub project, scheduled for a joint meeting of the American Geophysical Union,
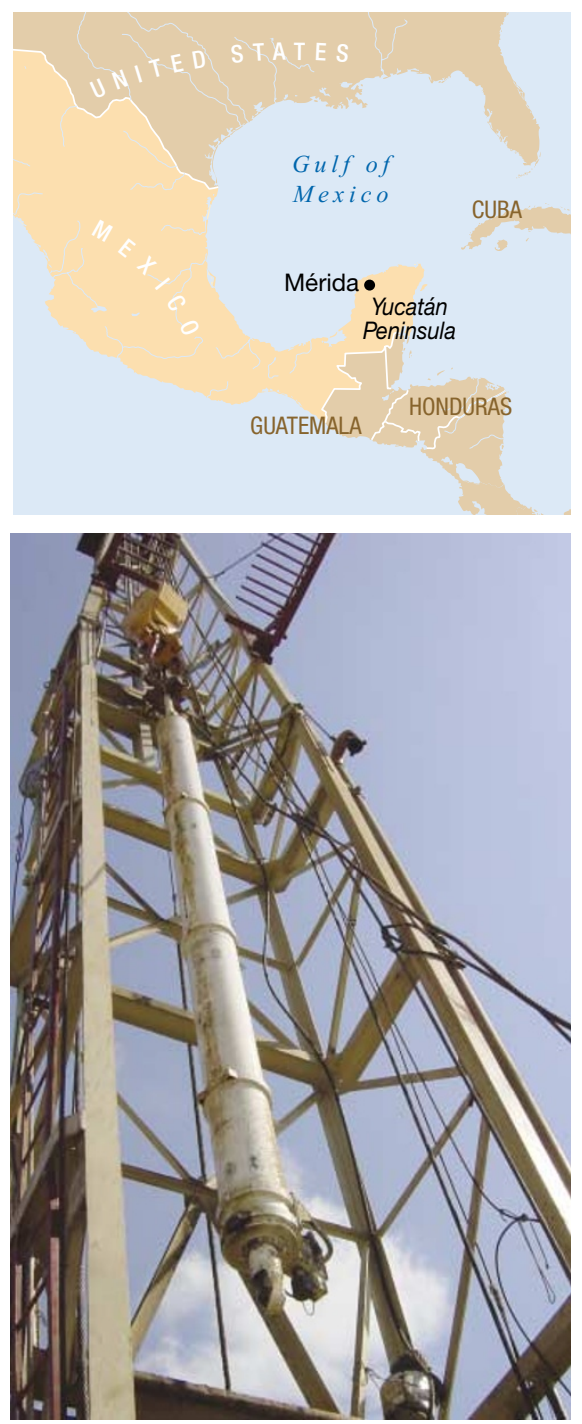

Cutting edge: the Chicxulub drill site is located near Mérida in Mexico's Yucatán Peninsula.

the European Geophysical Society and the European Union of Geosciences, to be held in Nice, France, in April.

Most of these researchers eventually received their samples in December. For geochemist Erika Elswick and her colleagues at Indiana University in Bloomington, this left insufficient time to analyse sulphur isotopes in the boundary core and compare the results with cores from four sites across North America. From this work, Elswick had hoped to discover how far debris from the impact was thrown into the air. And besides being late, the boundary core samples were too small for the tests she needed to run. "We were dismayed," says Elswick. "There was no explanation given; no apology." Ames similarly received insufficient material for her planned geochemical studies, which aimed to identify ancient hydrothermal vents in the crater. Smit acknowledges that some researchers did not receive sufficient samples, but says that they didn't complain to him.

Gerta Keller, a palaeontologist at Princeton University in New Jersey, pressed Smit hard to obtain samples for her studies of fossilized marine plankton known as foraminifera, most of which disappeared in the K/T extinction. Her analysis stunned the audience in Nice, suggesting that foraminifera continued to prosper for 300,000 years after the impact. Directly above the impact breccia - a layer of conglomerates that bears the marks of a powerful collision - Keller found foraminifera-rich sediments, which she dated using geochemical data and by analysing the microfossils they contained. The green line of the K/T boundary sat above these sediments. The Chicxulub impact, Keller concluded, could not have caused the mass extinction.

\section{Core issues}

Keller, who suspects that the K/T extinction was caused by a series of impacts, has long sparred with Smit, who is an enthusiastic supporter of the Chicxulub impact theory. She rejects his explanation for the delay in sending out the samples, claiming that "he tried to postpone our results so that he could remain unchallenged through the Nice meeting”.

Smit dismisses that allegation as "ridiculous", and disputes Keller's scientific conclusions. The sediments in question, he argues, were not laid down over 300,000 years, but were instead washed back into the crater shortly after the impact. He also claims that Keller has misidentified non-living crystals as microfossils. But other researchers back Keller's identifications - Rebolledo has also conducted palaeomagnetic analyses of other sections of the boundary core and confirmed her dates.

Despite Smit's rejection of Keller's data, other experts believe that she has raised serious doubts about the link between the impact and the K/T extinction. "We ought to look very carefully at this," says Sharpton, who has previously supported the Chicxulub impact theory. "If she is right, we have a real issue."

The various groups on the Chicxulub project are now preparing articles for a special issue of the journal Meteoritics \& Planetary Science, expected to appear next year. And from 30 September, researchers outside the project can submit requests to UNAM to analyse samples. Eventually, scientific consensus on whether or not the Chicxulub impact caused the K/T extinction may emerge. But the huge personal investment that many researchers in the field have put into their favoured theories is likely to ensure further acrimonious debate in the meantime. "It's not about science," claims Norman MacLeod, keeper of palaeontology at the Natural History Museum in London, who believes that sea-level changes and volcanism are more likely explanations for the K/T extinction. "It's about people's reputations."

Rex Dalton is Nature's US West coast correspondent. www.icdp-online.de/sites/chicxulub/news/ news.html 